Current psychology letters

\title{
The Effect of Glass Colour on the Evaluation of a Beverage's Thirst-Quenching Quality
}

\section{Nicolas Guéguen}

\section{(2) OpenEdition \\ 1 Journals}

\section{Electronic version}

URL: http://journals.openedition.org/cpl/398

DOI: $10.4000 / \mathrm{cpl} .398$

ISSN: $1379-6100$

\section{Publisher}

Centre PsyCLÉ

\section{Electronic reference}

Nicolas Guéguen, «The Effect of Glass Colour on the Evaluation of a Beverage's Thirst-Quenching Quality », Current psychology letters [Online], 11, Vol. 2, 2003 | 2003, Online since 30 March 2006, connection on 08 September 2020. URL : http://journals.openedition.org/cpl/398; DOI : https:// doi.org/10.4000/cpl.398

This text was automatically generated on 8 September 2020

(C) All rights reserved 


\title{
The Effect of Glass Colour on the Evaluation of a Beverage's Thirst- Quenching Quality
}

\author{
Nicolas Guéguen
}

\section{Introduction}

The effect of colours on human perception and human behaviour has been widely demonstrated in literature. Colour can affect perception and evaluation of environments and people. Rubinoff and March (1980) found that colour could have a significant influence on the judgement of personality characteristics of politicians. In their experiment, subjects were instructed to rate the personality of fictitious candidates presented by campaign posters in different colour combinations. For example, highest ratings of extroversion, honesty and experience were obtained for white on blue, and the lowest ratings for orange on blue.

The colours of the physical environment are thought to have important effects on human behaviour. Read, Sugawara and Brandt (1999) found that wall colours were related to levels of cooperative behaviour among preschool children. They found that a white ceiling compared to a red ceiling led children to lower levels of cooperation (i.e.: playing together with a toy).

Rubinoff and March (1980) found that colour influenced the judgement of personality characteristics of politicians but the effect of colour on actual voting behaviour was not measured. Garret and Brooks (1987) found that the colour of ballot papers (pink or green) influenced voters' choice. Female voters more favourably chose candidates whose details were displayed on pink paper, whereas male voters more favourably chose candidates whose details were displayed on green paper. Respondents' behaviour is also affected by colour of the questionnaire. Matteson (1974) had found, in a mailing survey, that a pink questionnaire compared to a white questionnaire increased the response rate significantly. 
Colours also affect consumer's behaviour. Sparkman and Austin (1980) found that onecolour newspaper ads instead of identical black-and-white ads led to the increase in median sales volumes of approximately $41 \%$.

The empirical studies presented here found that colours have an effect on perception, evaluation and behaviour. Surprisingly enough, only a few studies have been published that investigate the effect of colour on the evaluation of beverages and food. Furthermore, some researches exist in literature.

Colours of food and beverages have a significant effect on the quality and the intensity of perceived taste (Jonhson \& Clysdesdale, 1982; Jonhson, Dzendolet, Damon, Sawyer \& Clysdesdale, 1982; Pangborn, 1987). For Walsh, Toma, Tuveson and Sondhi (1989) variations in the perception of food and beverages qualities were explained by associations between colour and sensory qualities. Maga (1974) found that sucrose was detectable in a green aqueous solution at a concentration level that was below than a baseline (no colour) level whereas sucrose was detectable in a yellow solution at a concentration that was higher than the baseline level. It seems that, in this experiment, green was associated with a sweet taste whereas yellow was not.

An other situation where the influence of colours is studied is the effect of environmental factors on the preference for colour. Fanger, Breum and Jerking (1977) found that their subjects preferred lower ambient temperature in red light than in blue light. Physiological factors also have an influence. Kim and Kotura (1997) have found that their female subjects preferred warm colours during the luteal phase of their ovarian cycle than in the follicular phase. Previous study of these authors had shown that during the luteal phase, female-subjects felt cooler and preferred to wear cloth of warm colours (Kim \& Tokura, 1995). Cunningham and Cabanac (1971) have found that during the luteal phase, their female-subjects felt that warm coloured water poured on their hands was more pleasant, whereas cold coloured water was evaluated negatively. During the follicular phase, the reverse evaluation of the coloured water was observed suggesting that internal temperature, which varied during the ovarian cycle, had an influence on the sensation produced by different colours. Further effect of temperature had been found and did not imply physiological components. Kim and Tokura (1998) have found that their subjects significantly preferred clothes of warm colours under the influence of face cooling. Such findings suggest that ambient temperature have an impact on the preference for colours and that warm colours (red, orange, yellow) are preferred in cool temperatures whereas cold colours (blue, green) are preferred in hot temperatures. So, if colours have and impact on evaluation of food and beverages, and if they are associated with cool or warm temperatures, then colours could influence the perception of the thirst-quenching quality of a beverage. In order to test this aspect of colour, an experiment was carried out in which subjects had to test the same beverage presented in glasses of different primary colours. Afterwards, they were instructed to indicate the glass containing the most thirst-quenching beverage. It was hypothesis that beverage contained in glasses of cold colours (Blue, Green) would be associated with greater thirst-quenching quality than the same beverage contained in glasses of warm colours (Red, Yellow).

MethodSubjects

Forty undergraduate students (20 males and 20 females) in various disciplines (business, communication, computer-science...) aged between 18-20 ( $M=18.72 S D=$ 1.08). 
Procedure

Upon arrival to the laboratory, the subject was informed that the research was a taste task of a new soda. Then, the subject was introduced in a 3 㹂 3 meters room with a table dressed in the centre. The temperature of the room was controlled at $23^{\circ} \mathrm{C}$. On the table, 4 glasses of different colours (Blue, Green, Yellow, Red) were presented. All the glasses used in this experiment were identical except for the colour. All of them were opaque so no additive colours were created by the colour of the glass and the colour of the beverage. The same beverage was contained in each glass in an even proportion. One minute before the subject entered the experimental room, an assistant brought the glasses that were placed in a fridge at $10^{\circ} \mathrm{C}$. Each glass was separated from the other by a distance of 20 centimetres. In front of each glass a number of order (1, 2, 3 or 4) was printed on a sticker and set on the table. The colour of the glass corresponding to each number of orders was randomly attributed to each participant. The subject was instructed to taste each beverage contained in the glasses and then, after testing the 4 beverages, he/she had to indicate the glass containing the most thirst-quenching beverage. The experimenter also asked the subject to taste the beverages in the order in which they were presented. Then, the experimenter asked the subject if he/she had any question. If not, the experimenter invited the subject to taste the beverages. Once the subject had tested the 4 beverages, the experimenter asked him/her to indicate the most thirst-quenching beverage. Then, the experimenter reported the number order and the colour of the glass selected by the subject. He then thanked the subject for his/ her participation and then proceeded to his/her debriefing.

Results

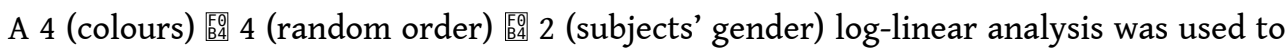

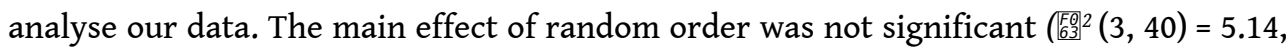
$p>.20)$. The main effect of the subject gender was also non significant $\left(\left[\begin{array}{ll}{[6-6} \\ 6\end{array}\right)^{2}(1,40)=2.28\right.$, $p>.10)$. Furthermore, a main effect of the colours was found $\left(\mathrm{EF}_{63}^{2}{ }^{2}(3,40)=12.20, p<.01\right)$.

No interaction effect between the subject' gender or the random order and the colours was found ( $p>.20$ in each case) so the data were aggregated. The proportions of the glass colours containing the beverage that was designed as the most thirst-quenching beverage is presented in table 1 hereafter.

Table 1 : Rate of subjects (in \%) who indicated the colour of the glass containing the most thirstquenching beverage

\begin{tabular}{|l|l|l|l|}
\hline \multicolumn{3}{|l|}{ Cold colours } & Warm colours \\
\hline Blue & Green & Yellow & Red \\
\hline 47.5 & 25.0 & 12.5 & 15.0 \\
\hline
\end{tabular}

When blue and green (cold colours) were aggregated and compared to yellow and red

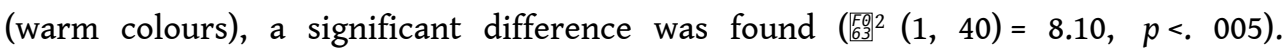
Comparisons by colours showed that Blue was clearly different from Red $\left(\left[\mathrm{F}_{63}\right)^{2}(1,24)=\right.$

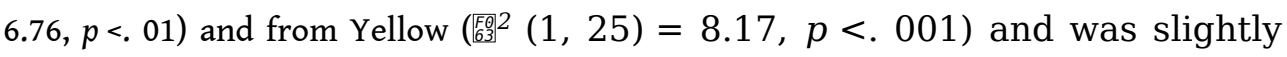
different from Green $\left({ }_{6-6}^{\left[F_{3}\right.} 2(1,29)=2.76, p<\right.$. 09). Two by two comparisons between Red, Yellow and Green did not shown any statistical difference ( $p .>.20)$.

Discussion 
The results of this study support the hypothesis according to which colours can influence the evaluation of beverages. These findings are in line with those of prior studies where evaluation of different aspects of food and beverage were tested (Jonhson \& Clysdesdale, 1982; Jonhson, Dzendolet, Damon, Sawyer \& Clysdesdale, 1982; Maga, 1974; Pangborn, 1987). The influence of colour on the perception of the thirstquenching quality of a beverage is a new dimension that confirms the influence of colour on perceived taste. In our experiment, cold colours (Blue and Green) were considered as the most thirst-quenching beverages whereas warm colours (Red and Yellow) were considered as the lower thirst-quenching beverages. These results confirmed the psychological distinction between warm colours such as Yellow, Red or Orange and cold colours such as Blue or Green (Wright, 1962). Among the four colours, Blue was associated with the most thirst-quenching beverage in nearly $50 \%$ of the cases. Such results confirm Walsh et al., (1989) who considered that perception of taste qualities were explained by associations between colour and sensory qualities. Studies have shown that colours are associated with different temperatures where Blue and Green were felt to be cooler, and Yellow and Red to be warmer (Wright, 1962). So, when subjects have to evaluate the thirst-quenching quality of beverages at the same temperature, the colour became information that was associated with a taste quality. Then glasses of cold colours were evaluated as containing the most thirst-quenching beverages, in comparison to glasses of warm colours.

of course this experiment was limited. The sample size was small and the population studied included only students. As a laboratory study, the empirical results presented here may not easily be extended to an external consumption environment. It would be interesting to analyse the effect of colours in different ambient temperatures and in real environments such as in bars or in restaurants. If this effect of colour on perception were confirmed, it would be interesting for managers of bars or restaurants to use glasses of various colours to create various sensations and perceptions among the regular customers.

Our results have shown that colour had an influence on the perception of a taste quality of beverage but a single taste quality was tested in this experiment. It would be interesting to test, with the same method, other dimensions associated with warm or cold colours such as perceived sweetness (Maga, 1974). Moreover, there were some methodological limitations in this experiment. Subjects were instructed to indicate the most thirst-quenching beverage. So it is possible that without any further information than the colour of glass, subjects were influenced by their favourite colour - Silver and Ferrante (1995) found that blue is the favourite colour of both sexes - to evaluate the beverage. Thus, given the preliminary nature of our experiment, further studies employing some variations in the methodology (i.e.: estimation of only one beverage with a scale) are now necessary. 


\section{BIBLIOGRAPHY}

Cunningham, D. \& Cabanac, M. (1971). Evidence from behavioural thermoregulatory responses of a shift in setpoint temperature related to the menstrual cycle. Journal of Physiology, 63, 236-238.

Fanger, P. Breum, N., \& Jerking, E. (1971). Can colour and noise influence man's thermal comfort? Ergonomics, 20, 236-238.

Garrett, J., \& Brooks, C. (1987). Effect of ballot colour, sex of candidate, and sex of college students of voting age on their voting behaviour Psychological Reports, 60, 39-44.

Johnson, J., \& Clydesdale, F. (1982). Perceived sweetness and redness in coloured sucrose solutions. Journal of Food Science, 47, 747-752.

Jonhson, J., Dzendolet, E., Damon, R., Sawyer, M., \& Clysdesdale, F. (1982). Psychophysical relationship between perceived sweetness and colour in cherry-flavoured beverages. Journal of Food Protection, 45, 601-606.

Kim, S., \& Tokura, H. (1995). Effects of menstrual cycle on dressing behaviour in the cold. Physiological Behavior, 58, 699-703.

Kim, S., \& Tokura, H. (1997). Cloth colour preference under the influence of menstrual cycle. Applied Human Science, 16, 149-151.

Kim, S., \& Tokura, H. (1998). Cloth colour preference under the influence of face cooling. Journal of Thermal Biology, 23, 335-340.

Maga, J. (1974). Influence of colour on taste thresholds. Chemical Senses \& Flavor, 1, 115-119.

Matteson, M. (1974). Type of transmittal letter and questionnaire colour as two variables influencing response rates in a mail survey. Journal of Applied Psychology, 39, 533-536.

Pangborn, R. (1987). Selected factors influencing sensory perception of sweetness. In J. Dodding (Ed.), Sweetness (pp. 49-66). New York: Springer-Verlag.

Read, M., Sugawara, A., \& Brandt, J. (1999). Impact of space and color in the physical environment on preschool children's cooperative behavior. Environment and Behavior, 31, 413-428.

Rubinoff, M., \& Marsh, D. (1980). Candidates and colors: An investigation. Perceptual and Motor Skills, 50, 868-870.

Silver C. \& Ferrante R. (1995). Sex differences in color preferences among an elderly sample. Perceptual and Motor Skills, 80, 920-922.

Sparkman, R., \& Austin, L. (1980). Effect on sales of colors in newspaper advertisements. Journal of Advertising, 9, 39-42.

Walsh, L., Toma, R., Tuveson, R., \& Sondhi, L. (1989). Color preference and food choice among children. The journal of Psychology, 124, 645-653.

Wright, B. (1962). The influence of hue, lightness, and saturation on apparent warmth and weight. American Journal of Psychology, 75, 232-241. 


\section{ABSTRACTS}

Studies have shown that colour can influence the evaluation of food and beverages. The purpose of this study was to test the influence of colour on the perceived thirst-quenching quality of beverages. Forty undergraduate students (20 males and 20 females) have tested the same beverage presented in glasses of different colours (Blue, Green, Yellow, Red). The subjects were instructed to test each of the glasses according to a random order. Afterwards, they had to indicate the most thirst-quenching glass. Results show a significant difference between the four colours where the blue glass was evaluated as the most thirst-quenching beverage.

Des recherches ont montré que la couleur peut influencer la façon dont on évalue les aliments et les boissons. L'objectif de cette recherche est d'étudier l'influence de la couleur sur la perception de la valeur désaltérante de breuvages. Quarante étudiants (20 de chaque sexe) avaient à goûter la même boisson dans des verres de différentes couleurs (bleu, vert, jaune, rouge) selon un ordre au hasard. Ils avaient ensuite à désigner le verre qu'ils trouvaient le plus désaltérant. Les résultats font apparaître des différences significatives entre les quatre couleurs, le verre bleu étant jugé comme contenant la boisson la plus désaltérante.

\section{INDEX}

Keywords: colour, influence, evaluation

\section{AUTHOR}

\section{NICOLAS GUÉGUEN}

Université de Bretagne-Sud

IUT de Vannes- Département TC

Laboratoire GRESICO

8 , rue Montaigne

BP 561 - 56017 VANNES - France

Nicolas.Gueguen@iu-vannes.fr 